\title{
LR-90 a new advanced glycation endproduct inhibitor prevents progression of diabetic nephropathy in streptozotocin-diabetic rats
}

\author{
J. L. Figarola1 ${ }^{1}$, S. Scott ${ }^{1}$, S. Loera ${ }^{2}$, C. Tessler ${ }^{3}$, P. Chu² ${ }^{2}$ L. Weiss ${ }^{2}$, J. Hardy ${ }^{4}$, S. Rahbar ${ }^{1}$ \\ ${ }^{1}$ Department of Diabetes and Endocrinology, Gonda Building, City of Hope National Medical Center, Duarte, USA \\ 2 Department of Anatomic Pathology, Beckman Research Institute of the City of Hope National Medical Center, Duarte, \\ California, USA \\ ${ }^{3}$ Animal Resources Center, Beckman Research Institute of the City of Hope National Medical Center, Duarte, California, USA \\ ${ }^{4}$ Electron Microscope Core Laboratory, Beckman Research Institute of the City of Hope National Medical Center, Duarte, \\ California, USA
}

\begin{abstract}
Aims/hypothesis. Advanced glycation and lipoxidation endproducts have been implicated in the pathogenesis of diabetic complications, including diabetic nephropathy. LR-90, a new advanced glycation endproduct inhibitor, was investigated for its effects on the development of renal disease in diabetic rats.

Methods. Diabetic animals were randomly allocated into groups receiving LR-90 or vehicle (untreated). Age- and weight-matched non-diabetic rats were studied concurrently. Body weight, plasma glucose, glycated haemoglobin, urinary albumin and creatine excretions were measured serially. Kidney histopathology, AGE accumulation in cells and tissues, protein oxidation, were also examined. In vitro assays were used to assess the possible mechanism of action of LR-90.

Results. LR-90 inhibited the increase in albumin and creatinine concentrations, and concentrations of circulating AGE in diabetic rats without any effect on glycaemic control. LR-90 treated-rats also showed higher body weights than untreated diabetic rats. LR-90 pre-
\end{abstract}

vented glomerulosclerosis, tubular degeneration and collagen deposition in the kidney. AGE-induced crosslinking and fluorescence of tail collagen were reduced by LR-90 treatment. LR-90 also decreased AGE accumulation in kidney glomeruli and nitrotyrosine deposition in the renal cortex. In vitro, LR-90 was capable of reacting with reactive carbonyl compounds and was a more potent metal chelator than pyridoxamine and aminoguanidine.

Conclusion/interpretation. LR-90 reduces in vivo AGE accumulation, AGE-protein cross-linking and protein oxidation, and could be beneficial in preventing the progression of diabetic nephropathy. The AGE inhibitory and therapeutic effects of LR-90 could be attributed, at least in part, to its ability to react with reactive carbonyl species and/or potent metal chelating activity that inhibits glycoxidative-AGE formation. [Diabetologia (2003) 46:1140-1152]

Keywords Glycation, nephropathy, proteinuria, diabetes, AGE inhibitor, carbonyl stress, oxidative stress, metal chelation, collagen, reactive carbonyl species.
Received: 26 November 2002 / Revised: 30 January 2003

Published online: 5 July 2003

(C) Springer-Verlag 2003

Corresponding author: S. Rahbar MD PhD, Department of Diabetes and Endocrinology, Gonda Building, City of Hope National Medical Center, 1500 E. Duarte Road, Duarte, California 91010, USA

E-mail: srahbar@coh.org
Abbreviations: AA, Ascorbic acid; AG, aminoguandine; ALE, advanced lipoxidation endproducts; CML, carboxymethyllysine; DNPH, 2,4'-dinitrophenylhydrazine; GLA, glycoaldehyde; GO, glyoxal; MGO, methylglyoxal; $\mathrm{NF}_{\kappa} \mathrm{B}$, nuclear factor $\mathrm{\kappa B}$; PM, pyridoxamine; RBC, red blood cells; RCS, reactive carbonyl species; ROS, reactive oxygen species; RPHPLC, reversed-phase high performance liquid chromatography; STZ, streptozotocin; TEM, transmission electron microscopy; UA/Cr, urinary albumin creatinine ratio. 
Advanced glycation/lipoxidation endproducts (AGE/ ALE) are a complex, heterogeneous, sugar/lipid derived irreverible protein modifications that have been implicated in the pathogenesis of diabetic complications, atherosclerosis, Alzheimer's disease and in the process of normal aging [1, 2, 3, 4, 5]. Both AGE and ALE are formed by carbonyl amine chemistry between protein residues and RCS. These RCS are constantly produced by the metabolism of carbohydrates, lipids and amino acids in the body $[6,7]$.

Both oxidative and non-oxidative pathways could form AGE. Autooxidation of glucose and oxidation of glycated residues are potent sources of free radicals that are enhanced in hyperglycaemia and might be the primary culprits in tissue damage. These reactions are catalysed by low concentrations of transition metals, particularly iron and copper, which are normally in a bound state but whose homeostasis could be compromised by diabetes and Alzheimer's disease $[8,9,10]$.

Oxidative stress is widely recognized as a key component in the development of diabetic complications. Increased ROS activity results in the production of AGE/ALE, increasing oxidative stress both in vitro and in vivo $[6,11,12,13]$. Accumulation of AGE and ALE is believed to increase the rate of chemical modification and cross-linking of tissue proteins, which in diabetes, contributes to the development of various diabetic complications.

Nephropathy is one of the most common complications of diabetes. In its early phase, the disease is characterized by increased albuminuria, glomerular hypertrophy and nephromegaly, followed by mesangial expansion, glomerulosclerosis and increased serum creatinine, and culminating in end-stage renal disease $[14,15,16,17]$. AGE and AGE cross-links have been proposed as contributing factors in the development and progression of diabetic nephropathy [18, 19]. Immunohistochemical observations in diabeticrat models have shown AGE accumulation in the glomerular extracellular matrix $[19,20]$. In human diabetic patients, the accumulation of AGE, in particular, CML, pentosidine and malondialdehyde in glomerular lesions, is related to disease severity and in the presence of an up-regulated receptor for AGE (RAGE) in podocytes [21, 22]. The toxic effects of these AGE result from structural and functional alterations in plasma and extracellular matrix (ECM) proteins, in particular, from cross-linking of proteins and interaction of AGEs with their receptors and/or binding proteins. This leads to enhanced formation of reactive oxygen species with subsequent activation of $\mathrm{NF}_{\mathrm{K}} \mathrm{B}$ and release of pro-inflammatory cytokines, growth factors, and adhesion molecules [16, 23, 24]. AGE accumulation in collagen, a long-lived structural protein in the extracellular matrix region of the kidney, is thought to effect changes in elasticity, ionic charge, thickness and turnover of basement membrane components [25]. These increase the number of large

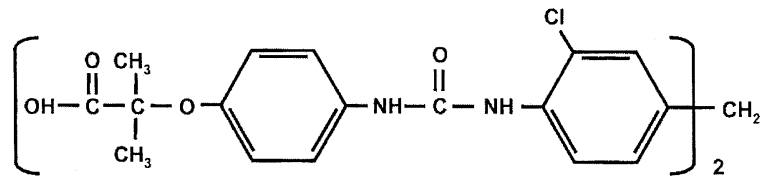

Fig. 1. The chemical structure of LR-90, methylene bis $\left[4,4^{\prime}-(2\right.$ chlorophenylureido phenoxyisobutyric acid)]

openings in the meshwork of the membrane, which further lead to an impairment of renal function.

A number of natural or synthetic compounds such as AGE inhibitors have been proposed, discovered or are currently being advanced [26, 27]. These AGE inhibitors exhibit two possible modes of action: attenuation of total AGE loads to prevent pathophysiological affects, and by chemical modifications of existing AGE structures and intermediates to non-active forms. Aminoguanidine (AG) was the first compound designed to inhibit AGE formation and cross-linking in vitro and in vivo, and has currently undergone Phase III clinical trials $[28,29]$. In vitro and animal models have shown the potential of other agents to reduce AGE accumulation. These include antioxidants such as vitamin $\mathrm{E}$ and lipoic acid, vitamin $\mathrm{B} 1$ derivatives and pyridoxamine, OPB-9195, ALT-946, metformin, teniseltam and EF655 [30, 31, 32, 33, 34, 35, 36, 37]. AGE cross-link breakers such as PTB and its derivative ALT-711 were also reported effective in vitro and in several animal studies [38, 39].

In the past seven years, our laboratory has been involved in the design and synthesis of compounds with possible AGE inhibitory effects. These aromatic compounds, mostly derivatives of aryl (and heterocyclic) ureido, and aryl (and heterocyclic) carboxamido phenoxy isobutyric acids, were screened and evaluated using several well-established in vitro assay methods. From these screens, 29 new compounds (out of 102) with AGE-inhibitory activities were developed [27, $40,41]$. Using various fluorescence and immunological techniques, these compounds were found to be multistage glycation inhibitors. Furthermore, LR-90 (Fig. 1) and some other compounds were more effective than pyridoxamine and aminoguanidine in vitro.

Earlier studies have reported that treatment of AGE inhibitors can confer renoprotection on diabetic rats and prevent development of diabetic nephropathy [35, $36,37,42,43)$. In this study, we aim to show the efficacy of using the new AGE inhibitor LR-90 in the treatment of experimental diabetes and to determine its potential in preventing the development of renal disease in a diabetic animal model. In addition, we examined whether the compound's therapeutic activity is dependent, at least in part, to its ability to react with RCS and chelate metal ions in glycoxidative AGE formation. 


\section{Materials and methods}

Materials. Male Sprague-Dawley rats ( 175 to $200 \mathrm{~g})$ were obtained from Charles River Laboratories (Wilmington, Mass., USA). Streptozotocin, pepsin, papain, $\mathrm{HCl}$, acetic acid, chloramine-T trihydrate, p-dimethylamino-benzaldehyde, trans-4hydroxyproline, citric acid monohydrate, 1-propanol, phosphate buffer saline mix ( $\mathrm{pH}$ 7.4), p-nitrophenyl phosphate, EDTA, and rabbit anti-rat IgG were obtained from Sigma Chemicals (St. Louis, Mo., USA). Perchloric acid was purchased from Mallindckrodt (Paris, Ky., USA). The clinical assay kits (Nephrat and Creatinine Companion kits) were from Exocell (Philadelphia, Pa., USA). Monoclonal anti-AGE antibody (6D12) was obtained from Cosmo Bio (Tokyo, Japan). LR-90, (methylene bis [4,4'-(2-chlorophenylureidophenoxyisobutyric acid)]) was synthesized by Dr. I. Lalezari (Chemiphar, Scarsdale, N.Y., USA). Unless otherwise noted, all immunohistochemical reagents were from DAKO (Carpinteria, Calif., USA).

Animal studies. All animal care, procedures and protocols were followed according to the policies outlined in "The Guide for the Care and Handling of Laboratory Animals" (NIH Publication No. 85-23) which have been approved by the City of Hope National Medical Center Research Animal Care Committee. After a one-week adaptation period, rats were rendered diabetic by intraperitoneal injection of STZ $(65 \mathrm{mg} / \mathrm{kg}$ in citrate buffer, $\mathrm{pH} 4.5$ ) after an overnight fast. Non-diabetic animals were injected with the buffer only. Diabetes was confirmed by measuring the plasma glucose concentrations 7 days after STZ-injection. Only animals with plasma glucose concentration of more than $20 \mathrm{mmol}$ were classified as diabetic and were used in the study. These diabetic rats were divided randomly into untreated diabetic control group and a diabetic treatment group receiving LR-90 at $50 \mathrm{mg} / \mathrm{l}$ in their drinking water. All animals were house individually and were given free access to food (Purina rodent chow 5001, Ralston Purina, Richmond, Ind., USA) and water. Every 8 weeks, blood (from the tail vein) and urine samples were collected from rats for glycaemic control analysis and albuminuria measurements.

Glycaemic control measurements. Glycaemia was monitored every 8 weeks by measuring plasma glucose and glycated haemoglobin. Plasma glucose was measured using a glucose analyser machine (YS1 2300, YSI, Yellow Springs, Ohio, USA). Glycated haemoglobin was measured by HPLC (Biorad, Hercules, Calif., USA).

Renal function. Progression of renal dysfunction was assessed by measuring urinary albumin to creatinine ratio $(\mathrm{UA} / \mathrm{Cr}$ ) and serum creatinine every 8 weeks. For urinary albumin and creatinine concentrations, rats were housed in metabolic cages (Nalgene, Nalge, Rochester, N.Y., USA) for $24 \mathrm{~h}$ and urine was collected in a collection beaker with several drops of toluene to inhibit microbial growth. Urinary albumin was quantified immunologically using the Nephrat kit and urinary creatinine was measured by the Creatinine Companion kit. Serum creatinine was measured using the Sigma kit No. 555-A.

Necropsy and tissue collection. At 32 weeks, the rats were weighed and anaesthetized with metofane, and blood was drawn by heart puncture and transferred into heparinized and non-heparinized vacutainer tubes on ice. These blood samples were later centifuged for plasma and serum collection respectively, and stored at $-70^{\circ} \mathrm{C}$ until the time of analysis. Rats were killed by over-anesthetization and cardiac puncture and the kidneys were removed immediately, weighed, decapsulated and rinsed in PBS buffer. Sections of the kidneys were stored in $10 \%$ NBF for subsequent microscopic examinations and immunohistochemistry. The tail of each individual rat was cut, removed and stored in $50 \mathrm{ml}$ conical tubes at $-70^{\circ} \mathrm{C}$ before the analysis.

Serum and $\operatorname{IgG}$ AGE measurements. Serum AGE was measured according to [44] and quantified using polyclonal R6/9 anti-AGE RNAse antibodies [40]. IgG cross-linked to the surface of RBC was determined with an anti-IgG antibody by a modification of the method described by [38]. Briefly, heparinized blood was centifuged at $200 \mathrm{~g}$ for $5 \mathrm{~min}$ and the RBC were washed thrice with PBS and packed with a final centrifugation of $500 \times \mathrm{g}$. The cells were then diluted 1:100 with PBS and $50 \mu \mathrm{l}$ aliquot was added to wells of a 96-well Multiscreen Millipore microplate (Millipore, Bedford, Mass., USA) that was first blocked by Superblock buffer (Pierce Chemicals, Rockford, Ill., USA). Then $50 \mu \mathrm{l}$ of polyclonal rabbit anti-rat IgG conjugated to alkaline phosphatase (diluted 1:2500) was added to the wells and the microplate was incubated at room temperature for $2 \mathrm{~h}$. After incubation, the RBC were washed with PBS three times and once with $50 \mathrm{mmol} / \mathrm{l}$ Tris-buffered saline, $\mathrm{pH} 8.0$, and $100 \mu \mathrm{l}$ of $p$-nitrophenyl phoasphate substrate was added and incubated at room temperature. After $30 \mathrm{~min}$, absorbance was measured at $410 \mathrm{~nm}$ using a microplate reader.

Isolation and analysis of tail tendon collagen. Isolation and preparation of tail tendon collagen was done according to [45]. The relative degree of cross-linking and AGE formation in collagen was assessed by the following methods:

Pepsin digestion. Total pepsin digestion was done as described previously [46]. Collagen samples of $10 \mathrm{mg}$ from individual rats were digested with pepsin $(50 \mu \mathrm{g} / \mathrm{ml}$ in $0.5 \mathrm{~mol} / \mathrm{l}$ acetic acid) for $24 \mathrm{~h}$ at $37^{\circ} \mathrm{C}$. After digestion, the samples were centrifuged at $3000 \mathrm{rpm}$ for $30 \mathrm{~min}$ at $4{ }^{\circ} \mathrm{C}$ and the clear supernatant containing the digested collagen was collected. A total of $100 \mu \mathrm{l}$ aliquot of the supernatant were mixed with $900 \mu \mathrm{l}$ PBS buffer and the fluorescence of the sample was quantified at $365 \mathrm{~nm}$ excitation and $418 \mathrm{~nm}$ emission using a Hitachi F2000 fluorescence spectrophotometer (Hitachi, Tokyo, Japan). The hydroxyproline content of the supernatant was determined following acid hydrolysis using a microassay method of [47].

Papain digestion. Papain digestion was done as described previously [48]. Collagen samples of $5 \mathrm{mg}$ from individual rats were digested with $500 \mu \mathrm{l}$ papain solution $(2.5 \mathrm{units} / \mathrm{ml}$ papain in $50 \mathrm{mmol} / \mathrm{l}$ phosphate buffer, $\mathrm{pH} 6.5,2 \mathrm{mmol} / \mathrm{l}$ L-cysteine and $2 \mathrm{mmo} / \mathrm{l} \mathrm{EDTA}$ ) for $2 \mathrm{~h}$ at $65^{\circ} \mathrm{C}$ for $24 \mathrm{~h}$ at $37^{\circ} \mathrm{C}$. After digestion, the samples were centrifuged at $18,000 \mathrm{rpm}$ for $60 \mathrm{~min}$ at $4^{\circ} \mathrm{C}$ and the clear supernatant containing the digested collagen was collected. At total of $100 \mu \mathrm{l}$ aliquot of the supernatant were mixed with $900 \mu \mathrm{l}$ PBS buffer and the fluorescence of the sample was quantified at $370 \mathrm{~nm}$ excitation and $440 \mathrm{~nm}$ emission using a fluorescence spectrophotometer. The hydroxyproline content of the supernatant was also determined following acid hydrolysis as indicated above.

Acid solubility. The solubility of tail tendon collagen was measured by a modification of the method outlined in [45]. Briefly, $2 \mathrm{mg}$ of collagen samples were weighed and digested with pep$\sin (5 \mu \mathrm{g}$ pepsin/mg collagen in $1 \mathrm{mmol} / \mathrm{l}$ acetic acid) for $1.5 \mathrm{~h}$ at $4^{\circ} \mathrm{C}$. After digestion, the samples were centrifuged at $18,000 \mathrm{rpm}$ for $60 \mathrm{~min}$ at $4^{\circ} \mathrm{C}$. The supernatant was collected and both the volume of the supernatant and pellet were determined. Aliquots $(100 \mu \mathrm{l})$ of the supernatant and all of the pellets 
were acid hydrolyzed and analysed for their hydroxyproline content, which was assumed to make up $14 \%$ collagen by weight. The recoverable collagen was defined as the sum of collagen in the supernatant and pellet after digestion and percent solubility was defined as the amount of collagen in the supernatant fraction in relation to the total recoverable collagen [45].

Glomerulosclerosis, cortical tubule degeneration and cellular infiltrates. Glomerulosclerosis was defined as glomerular basement membrane thickening, mesangial hypertrophy, and capillary occlusion [49]. For quantifying glomerulosclerosis, kidney sections were stained with periodic acid Schiff (PAS) reagent. A total of 150 glomeruli were randomly chosen from each rat kidney (four different kidneys per treatment) and carefully graded for sclerosis, whereby the evaluator did not have prior knowledge of the identity of each kidney. The degree of sclerosis in each glomerulus was graded subjectively on a scale of 1 to 4: grade 1, sclerotic area less than $25 \%$; grade 2, sclerotic area 25-49\%; grade 3, sclerotic area 50-74\%; and grade 4, sclerotic area less than $75 \%$. The glomerulosclerotic index (GSI) was then calculated using the following formula: $\mathrm{GSI}=\sum_{\mathrm{i}=1}^{4} \mathrm{Fi}(\mathrm{i})$, where $\mathrm{Fi}$ is the percentage of glomeruli in the rat with a given score of (i) [49].

Cellular infiltrates were identified in the renal interstitium from $5 \mu \mathrm{m}$-thick kidney sections stained with PAS. Infiltrates in each kidney sample were graded as follows: + (patchy and light), ++ (patchy and dense), +++ (diffuse and dense with aggregates of neutrophils in tubules or in interstitium). As with the GSI calculation, the evaluator had no prior knowledge of the identity of the kidney sections to be graded.

For collagen deposition staining in the kidneys, paraffin sections were randomly chosen from kidneys from each treament group and stained with Masson's trichrome. Briefly, the sections were deparaffined, hydrated with water, and immersed in Mordant in Boiuin's solution for $10 \mathrm{~min}$. The sections were then rinsed in water and stained with Mayer's haematoxylin for $6 \mathrm{~min}$. After rinsing in water, Biebrich scarlet-acid fuchsin was added for $2 \mathrm{~min}$, rinsed, phosphomolybdic-phosphotungstic solution added for $15 \mathrm{~min}$, followed by aniline blue solution for $10 \mathrm{~min}$. After rinsing the sections with water, glacial acetic acid was added for $20 \mathrm{~s}$ and then the slides dehydrated with $95 \%$ ethanol. Blue and red colors indicate collagen and cytoplasm staining, respectively. Degenerated tubules were identified by the absence of cytoplasm.

Renal morphometry. Formalin-fixed samples of kidneys from each group were post-fixed with $2 \%$ glutaraldehyde overnight in cacodylate buffer. Sections were cut to $1 \mu \mathrm{m}$ thickness and stained with Toluidine Blue. Then $80 \mathrm{~nm}$ sections were cut with a diamond knife, picked up on formvar coated-carbon coated slot copper grids and stained with 5\% aqueous uranyl acetate for $15 \mathrm{~min}$, followed by $2 \mathrm{~min}$ on a drop of lead citrate. The grids were observed and photographed with a Philips CM10 transmission electron microscope (Philips Electronics, Mahwah, N.J., USA) and the images were used to determine the width of the glomerular basement membrane and mesangial expansion.

Immunohistochemistry, for AGE For immunohistochemicalAGE staining, formalin-fixed parafilm embedded section cuts ( $2 \mu \mathrm{m}$ thick) were mounted on slides coated with 2 -aminopropyltriethoxy silane, baked for $3 \mathrm{~h}$ at $58^{\circ} \mathrm{C}$, deparaffinized, rinsed with $3 \%$ hydrogen peroxide, and incubated with Proteinase $\mathrm{K}(0.5 \mathrm{mg} / \mathrm{ml})$ for $5 \mathrm{~min}$ at room temperature. These sections were washed with rinse buffer and blocked with Protein Blocking Agent for $5 \mathrm{~min}$ and subsequently incubated with 6D12 anti-AGE mouse monoclonal antibody for $30 \mathrm{~min}$ at room temperature. After washing with rinse buffer, the sections were incubated with EnVision + labelled polymer peroxidase-conjugated mouse anti-IgG for $30 \mathrm{~min}$ at room temperature, followed by detection with 3, 3'-diaminobenzidine tetrahydrochoride solution as chromogen and $50 \%$ haematoxylin as counterstain.

Immunohistochemical detection of nitrotyrosine. A method for nitrotyrosine detection in kidneys was reported previously [50] and followed in this study with little modification. Briefly, formalin-fixed kidney sections ( $5 \mu \mathrm{m}$ thick) taken from representative rats from each treatment group at 32 weeks were mounted on slides, dewaxed and hydrated. After incubation with Proteinase $\mathrm{K}$ for $10 \mathrm{~min}$, sections were incubated in $3 \%$ hydrogen peroxide for $20 \mathrm{~min}$, blocked with normal porcine serum for $20 \mathrm{~min}$, and then stained with rabbit polyclonal anti-nitrotyrosine antibodies (Upstate Biotechnology, Lake Placid, N.Y., USA) for $1 \mathrm{~h}$. After rinsing with DAKO rinse buffer, sections were incubated with biotinylated anti-rabbit IgG (Vector Laboratories, Burlingame, Calif., USA) for $25 \mathrm{~min}$, followed by incubation with avidin-biotin horse-radish peroxidase complex (Vectastain ABC Elite Kit, Vector Laboratories) for $25 \mathrm{~min}$. Localization of peroxidase conjugates was revealed using diaminobenzidine tetrahydrochloride (DAB) solution as chromogen and 50\% haematoxylin as counterstain.

Inhibition of copper-catalyzed oxidation of ascorbic acid. This assay was carried out according to [51], which measures the kinetics of copper-catalyzed oxidation of ascorbic acid (AA) in vitro. Briefly, $\mathrm{CuCl}_{2}$ and various concentrations of LR-90 were pre-incubated in chelex-treated $20 \mathrm{mmol} / \mathrm{l}$ phosphate buffer, $\mathrm{pH} 7.4$, for $5 \mathrm{~min}$, then ascorbic acid was added $(50 \mu \mathrm{l}$ of $10 \mathrm{mmol} / \mathrm{l}$ in water) to initiate the reaction $(1 \mathrm{ml}$ total reaction volume). The final concentration of $\mathrm{CuCl}_{2}$ and ascorbic acid in the reaction were $500 \mathrm{nmol} / \mathrm{l}$ and $500 \mu \mathrm{mol} / \mathrm{l}$, respectively. Aliquots $(135 \mu \mathrm{l})$ were removed at 0 and $60 \mathrm{~min}$ and transferred to autoinjector vials containing $15 \mu \mathrm{l}$ of $10 \mathrm{mmol} / \mathrm{l}$ DTPA. Samples were analysed by RP-HPLC using Waters 2690 Separator Module and Millenium 32 software (Waters Corporation, Milford, Mass., USA), equipped with auto-injector using a XTerra RP18 column (250 mm×4.6 mm, $5 \mu \mathrm{m})$ and a XTerra RP18, $5 \mu \mathrm{m}$ guard column. Solvents and gradient were all used as described [51]. The absorbance of ascorbic acid was measured at $244 \mathrm{~nm}$ and the peak area was determined to estimate the percent of ascorbic acid remaining versus time. The concentration of each inhibitor compound that inhibited the rate of AA oxidation by $50 \%\left(\mathrm{IC}_{50}\right)$, was calculated with respect to the control using Prism (Graph Pad Prism, San Diego, Calif., USA).

Scavenging of carbonyl intermediates of AGE formation. We evaluated the ability of LR-90 to interact with various RCS in vitro. Experimental procedures, incubation conditions, and determination of reactive-carbonyl and dicarbonyl groups were all done according to [52]. Briefly, $15 \mathrm{mmol} / \mathrm{l}$ of LR-90 was incubated with $10 \mathrm{mmol} / \mathrm{l} \mathrm{GO}$, MGO or GLA solutions. The concentrations of GO and MGO (after $24 \mathrm{~h}$ incubation) time were determined using Girard's reagent and the concentration of GLA (after 72-h incubation) was determined by the DNPH assay. Similar experiments were done using PM and metformin, two AGE inhibitors with carbonyl scavenger properties. Additionally, parallel experiments with carbonyl compounds incubated under the same conditions but without the inhibitor compound were used as controls for calculating the relative amount of remaining reactive carbonyl groups.

Data analyses. Statistical analyses were done by using GraphPad Prism (San Diego, Calif., USA). Data were first analysed 
Table 1. Effects of LR-90 on body weight and metabolic parameters in STZ-diabetic rats

\begin{tabular}{|c|c|c|c|c|c|c|}
\hline Group & $n$ & Body wt. (g) & $\begin{array}{l}\text { Plasma } \\
\text { Glucose } \\
(\mathrm{mmol} / \mathrm{l})\end{array}$ & $\begin{array}{l}\mathrm{HbA}_{1 \mathrm{c}} \\
(\%)\end{array}$ & $\begin{array}{l}\text { Serum } \\
\text { Creatinine } \\
(\mu \mathrm{mol} / 1)\end{array}$ & $\begin{array}{l}\mathrm{UA} / \mathrm{Cr} \\
(\mathrm{mg} / \mathrm{mg})\end{array}$ \\
\hline ND+LR-90 & 5 & $723.0 \pm 21.9$ & $6.8 \pm 0.7$ & $1.5 \pm 0.1$ & $39.8 \pm 21.2$ & $0.57 \pm 0.16$ \\
\hline $\mathrm{D}$ & 7 & $267.2 \pm 71.3^{\mathrm{a}}$ & $31.3 \pm 5.3^{\mathrm{a}}$ & $3.8 \pm 0.2^{\mathrm{a}}$ & $264.3 \pm 42.7^{a}$ & $3.32 \pm 1.37^{\mathrm{a}}$ \\
\hline D+LR-90 & 8 & $337.6 \pm 26.6^{b}$ & $28.9 \pm 3.4^{\mathrm{a}}$ & $3.3 \pm 0.4^{\mathrm{a}}$ & $142.3 \pm 47.7^{b}$ & $1.57 \pm 0.49^{b}$ \\
\hline
\end{tabular}

a $p<0.01$ vs non-diabetic control rats; ${ }^{\mathrm{b}} p<0.05$ vs. diabetic rats

by ANOVA and post hoc comparisons between group means were analysed using unpaired Student's $t$ test. A $p$ value of less than 0.05 was considered statistically significant. Data are presented as means \pm SD unless otherwise indicated.

\section{Results}

Glycaemic control, animal weights and mortality. Diabetic rats had increased plasma glucose and glycated haemoglobin concentrations compared to the control rats $(p<0.01$, Table 1$)$. Diabetes was also associated with reduced weight gain. Treatment of diabetic rats with LR-90 did not affect plasma glucose and glycated haemoglobin concentrations, but showed a slightly significant increase in weight compared to the diabetic control rats $(p=0.037)$. Two rats from the diabetic control group did not reach the end of the 32-week study period and died from unknown causes, presumably due to diabetic complications, compared to only one from the LR-90 treated-rats. No mortality was recorded from non-diabetic control rats and those non-diabetic rats treated with LR-90.

Renal function. Both UA/Cr and serum creatinine concentrations were used as indicators of renal function. In contrast to non-diabetic control rats, urinary albumin increased with time in all diabetic groups. At 32 weeks, diabetic control rats had higher UA/Cr $(p<0.01)$ and serum creatinine $(p<0.01)$ than non-diabetic rats (Table 1). LR-90 treatment inhibited the rise in UA/Cr, with about a $50 \%$ reduction in concentration compared to untreated diabetic rats. In addition, serum creatinine concentrations was decreased by LR-90 by more than $40 \%$ compared with diabetic control rats.

Serum and $\operatorname{Ig} G A G E$. Diabetic rats had about $5 \times$ higher concentrations of AGE in serum and in the surface of RBC compared to non-diabetic rats $(p<0.05$, Fig. 2). LR-90-treated rats showed less AGE in both serum and in the surface of RBC compared to untreated diabetic rats, reducing both AGE concentrations up to $40 \%$ toward the concentrations in non-diabetic control animals.

Collagen cross-linking and fluorescence. The concentrations of flourescent AGE in tail collagen as mea-
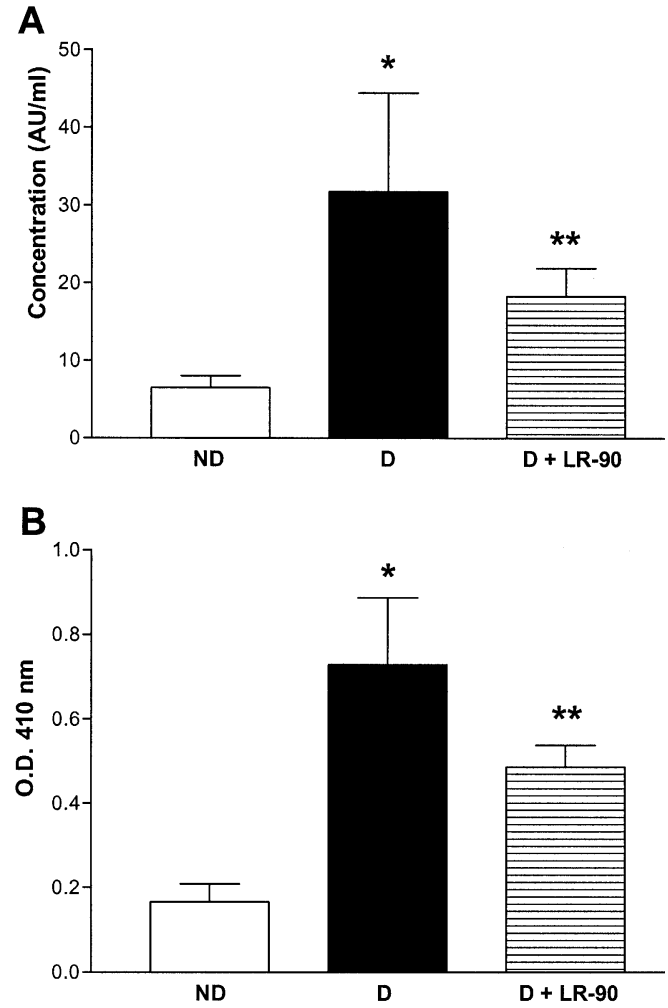

Fig. 2A, B. Effects of diabetes and LR-90 treatment on (A) serum AGE and (B) IgG-AGE on surface of RBC. Blood samples from rats were collected after 32 weeks and red blood cells and sera isolated. The levels of cross-linked IgG-AGE on the surface of red blood cells were determined with an antiIgG antibody. Serum AGE was measured immunologically using anti-AGE RNAse polyclonal antibodies. One AU was assumed equivalent to $1 \mu \mathrm{g} / \mathrm{ml}$ AGE-BSA. For this and subsequent figures, $N D$ non-diabetic rats; $D$ diabetic rats; $D+L R-90$ LR-90 treated diabetic rats; $* p<0.05$ vs non-diabetic rats; $* * p<0.05$ vs diabetic rats

sured by both pepsin and papain digestions were increased about fourfold in diabetic rats compared to non-diabetic rats after 8 months of diabetes (Fig. 3). LR-90-treated diabetic rats showed a reduction of fluorescence compared with untreated diabetic rats $(24 \%$ and $17 \%$ for pepsin and papain digests, respectively), but was still higher than the concentrations observed in non-diabetic rats. Similarly, when collagen samples 


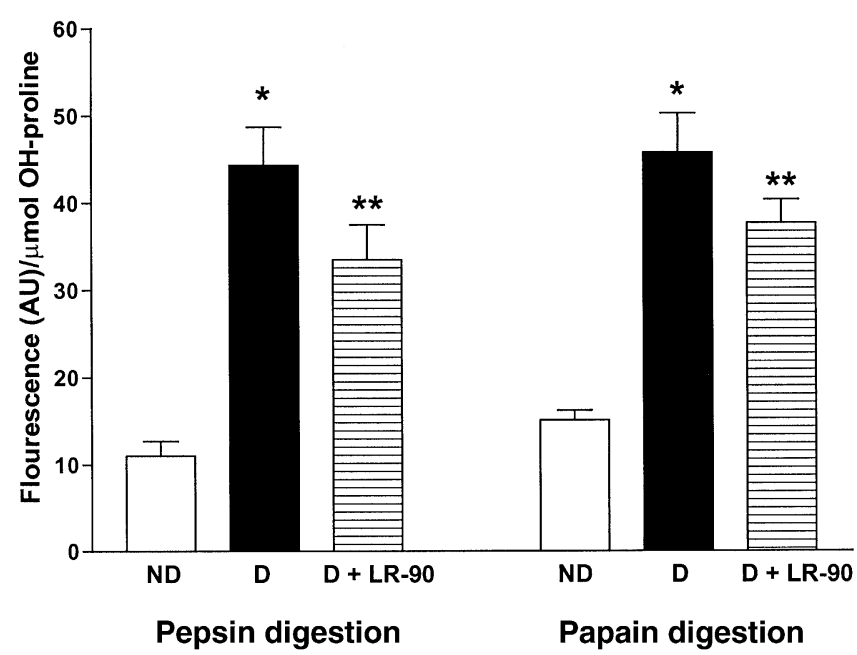

Fig. 3. Effects of diabetes and LR-90 treatment on levels of fluorescent AGE in tail tendon collagen digested with pepsin and papain. Tail tendon collagen was isolated and $10 \mathrm{mg}$ of collagen samples from individual rats ( $n=4$ per group) were digested with pepsin $(50 \mu \mathrm{g} / \mathrm{ml}$ in $0.5 \mathrm{~mol} / \mathrm{l}$ acetic acid) for $24 \mathrm{~h}$ at $37^{\circ} \mathrm{C}$. The supernatants were analysed for fluorescence (excitation $365 \mathrm{~nm}$ and emission $418 \mathrm{~nm}$ ) and hydroxyproline content. For papain digestion, $5 \mathrm{mg}$ of collagen samples from individual rats ( $n=4$ per group) were digested with $500 \mu \mathrm{pa}$ pain solution ( 2.5 units $/ \mathrm{ml}$ papain in $50 \mathrm{mmol} / \mathrm{l}$ phosphate buffer, $\mathrm{pH}^{\circ} 6.5,2 \mathrm{mmol} / 1 \mathrm{~L}$-cysteine and $2 \mathrm{mmol} / \mathrm{l}$ EDTA) for $2 \mathrm{~h}$ at $65^{\circ} \mathrm{C}$. The supernatants were analysed for fluorescence (excitation $370 \mathrm{~nm}$ and emission $440 \mathrm{~nm}$ ) and hydroxyproline content. Fluorescence was expressed as arbitrary units $(\mathrm{AU}) / \mu \mathrm{mol}$ of hydroxyproline digested

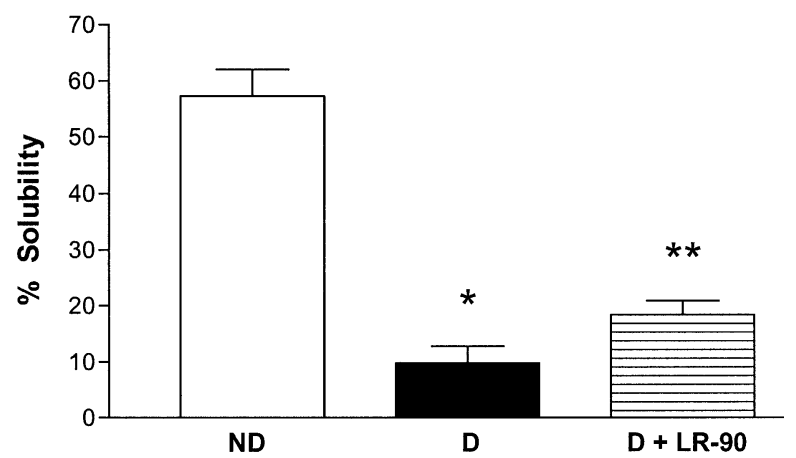

Fig. 4. Effects of diabetes and LR-90 treatment on tail tendon solubility. Tail tendon collagen was isolated and $2 \mathrm{mg}$ of collagen samples from each rat ( $n=4$ per group) were weighed and digested with pepsin $(5 \mu \mathrm{g} / \mathrm{mg}$ collagen in $1 \mathrm{~mol} / \mathrm{l}$ acetic acid $)$ for $1.5 \mathrm{~h}$ at $4^{\circ} \mathrm{C}$. The supernatant and the pellet were analyzed for their hydroxyproline content (which was assumed to make up $14 \%$ of collagen by weight). Percent solubility was calculated as described in the Methods section

were analysed for acid solubility, diabetic rats showed fivefold less solubility than non-diabetic rats, and LR90 treatment increased solubility by about $50 \%$ (Fig. 4).

Kidney anatomy and histopathology. Mean kidney weights, both in absolute weight and as a fraction of

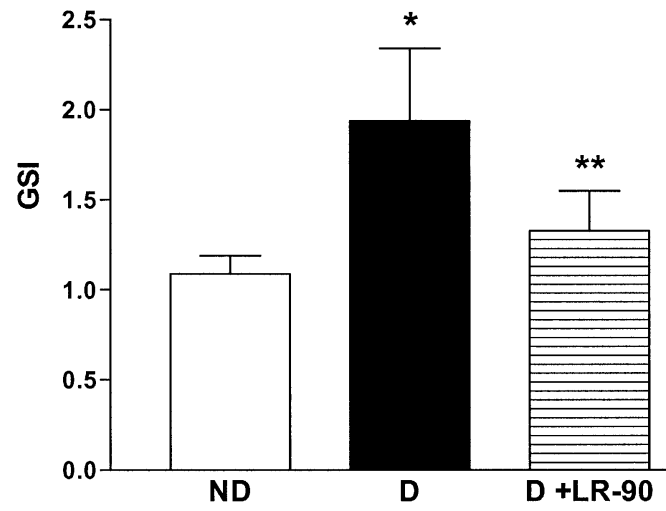

Fig. 5. GSI in kidneys from non-diabetic, diabetic and diabetic rats treated with LR-90. Formalin-fixed kidney sections $(2 \mu \mathrm{m}$ thick) taken from representative rats $(n=4)$ from each treatment group at 32 weeks were mounted on slides and stained with periodic acid Schiff reagent. The degree of glomerular injury was calculated using GSI as described in Methods

Table 2. Cellular infiltrates in the renal interstitium of non-diabetic, diabetic and diabetic rats treated with LR-90

\begin{tabular}{llll}
\hline Cases & $n$ & Cellular infiltrates & Grade $^{\mathrm{a}}$ \\
\hline Non-diabetic & 4 & none & 0 \\
Diabetic & 4 & lymphocytes, neutrophils & +++ \\
Diabetic + LR-90 & 4 & lymphocytes & +
\end{tabular}

a Infiltrates were graded as follows: + (patchy and light), ++ (patchy and dense), +++ (diffuse and dense with aggregates of neutrophils in tubules or in interstitium)

total body weight, were increased in diabetic rats compared to non-diabetic animals, but there were no statistically significant differences detected between LR-90 treatment and untreated diabetic control rats. Occasional cysts were observed in kidneys of diabetic control animals, but these were not increased in frequency in LR-90-treated rats. Moreover, there was no evidence of tumour growths in other major organs (heart, liver, intestines) from both untreated and LR90-treated diabetic animals. No considerable ultrastructural abnormalities in kidneys were detected from the non-diabetic rats, except for a few thickened basement membranes and a few cases of glomerulosclerosis (Fig. 5). Most of the glomeruli showed a normal ultrastructural appearance with normal cellularity, a normal mesangium, and a basement membrane of about $150 \mathrm{~nm}$ as revealed by TEM. No cellular infiltrates were detected in the renal interstitium from these animals (Table 2). In untreated diabetic rats, TEM data indicated that many glomeruli showed thickened basement membranes (about $270 \mathrm{~nm}$ ) with markedly increased cellularity and increased mesangial cells and matrix, and this was reflected by an increased GSI (Fig. 5). Also, there were a number of cellular infiltrates observed, including dense aggregates of lymphocytes and neutrophils (Table 2). Dia- 

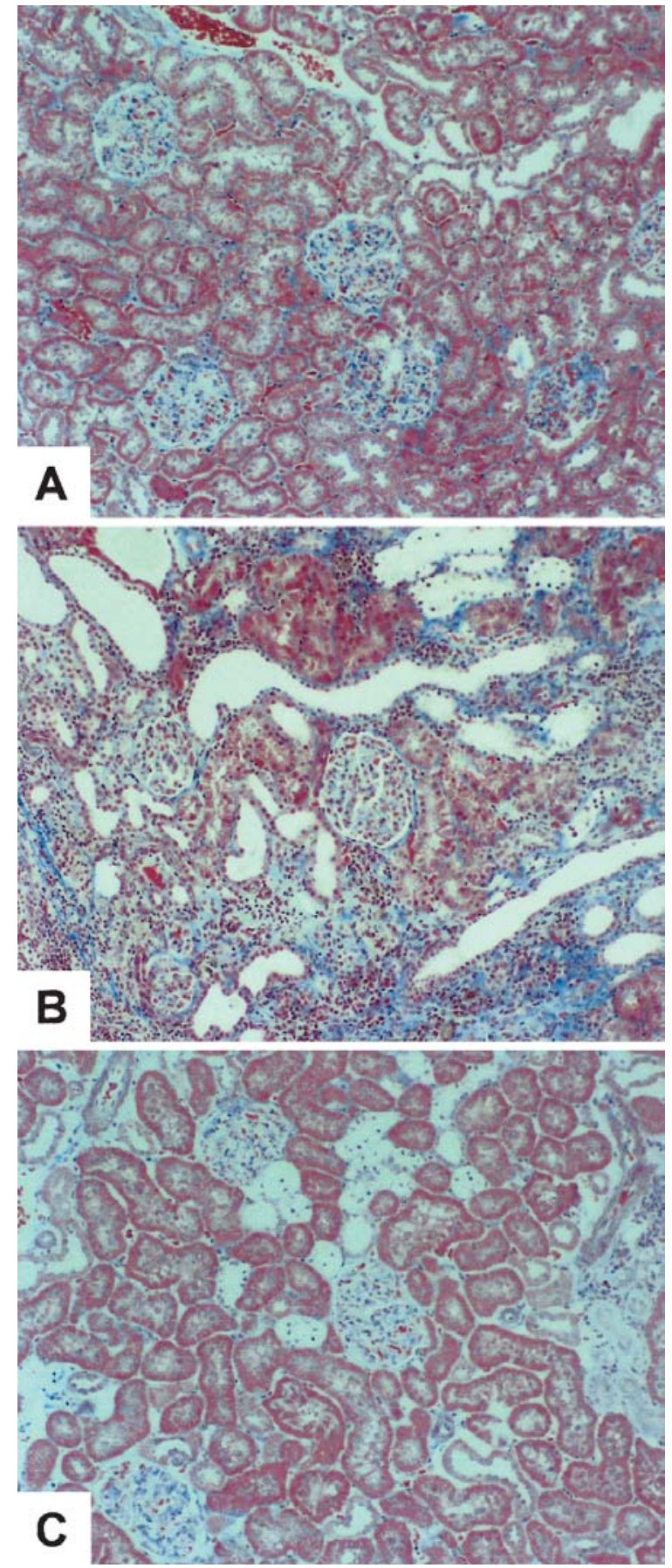

Fig. 6A-C. Collagen deposition and cortical tubule degeneration in kidneys from non-diabetic, diabetic and diabetic rats treated with LR-90. Formalin-fixed kidney sections $(2 \mu \mathrm{m}$ thick) taken from representative rats from each treatment group at 32 weeks were mounted on slides and stained with Masson's trichome. Blue and red colors indicate collagen deposition and cytoplasm staining, respectively. (A) non-diabetic; (B), diabetic; (C) diabetic + LR-90. Results shown are representative images from kidney samples from each group

betic rats treated with LR-90 also showed an increase in cellularity, although less markedly than that of untreated diabetic animals. Only lymphocytes were observed in the renal interstitium (Table 2). In addition, there was less glomerular damage, thinner basement membrane $(\sim 240 \mathrm{~nm})$, and lower GSI than untreated diabetic rats $(p<0.05$, Fig. 5). Moreover, both collagen deposition (blue color) in the tubulointerstitium and glomeruli, and the number of degenerate tubules (identified by the absence of cytoplasm or reddish color), were increased in diabetic rats compared with the non-diabetic control rats, and LR-90 treatment reduced the amount of collagen staining and frequency of degenerate tubules to an almost similar extent to that of the non-diabetic control rats (Fig. 6).

Immunohistochemistry for AGE. Immunohistochemical staining for AGE in rat kidney showed that there was widespread staining for AGE in the kidney glomeruli and the cortical tubules in diabetic rats compared with the non-diabetic control rats (Fig. 7A,B). Treatment of LR-90 visibly reduced the AGE deposited in these regions (Fig. 7C).

Nitrotyrosine staining. Nitrotyrosine, a marker for protein oxidation, was used as an index of oxidative tissue damage caused by reactive nitrogen species. Nitrotyrosine was predominantly detected in the renal tubules and few stainings were visible in the glomeruli (Fig. 8). Increased nitrotyrosine staining was observed in the renal tubules of diabetic rats compared with non-diabetic animals, and LR-90 treatment of diabetic animals attenuated this increased staining.

Metal chelation activity. Comparisons of the $\mathrm{Cu}{ }^{2+}$ chelating activity of LR-90 with AG and PM are shown (Fig. 9). In this assay, the $\mathrm{IC}_{50}$ values of LR90, PM and AG were $275 \mu \mathrm{mol} / 1,1250 \mu \mathrm{mol} / \mathrm{l}$, $2750 \mu \mathrm{mol} / \mathrm{l}$, respectively. These results indicate that in vitro, LR-90 was a more potent metal chelator than both known AGE inhibitors AG and PM.

Reaction of LR-90 with RCS. Because most AGE inhibitors are known to interact with several RCS intermediates of AGE/ALE formation, we tested whether LR-90 can also interact with these compounds in vitro. The carbonyl and dicarbonyl trapping activities of LR-90 compared with AGE inhibitors with known carbonyl scavenger activity such as PM and metformin are shown (Fig. 10). LR-90 reacted with all three RCS, and was noticeably more reactive than PM with MGO. Using various concentrations of LR-90 a similar test indicated that the new compound interacts with these RCS in a concentration-dependent manner.

\section{Discussion}

LR-90 belongs to a group of new aromatic compounds derived from LR-16, a compound that acts as an allosteric effector synergistic with 2,3-bisphosphoglycerate in increasing the oxygen affinity of haemoglobin 

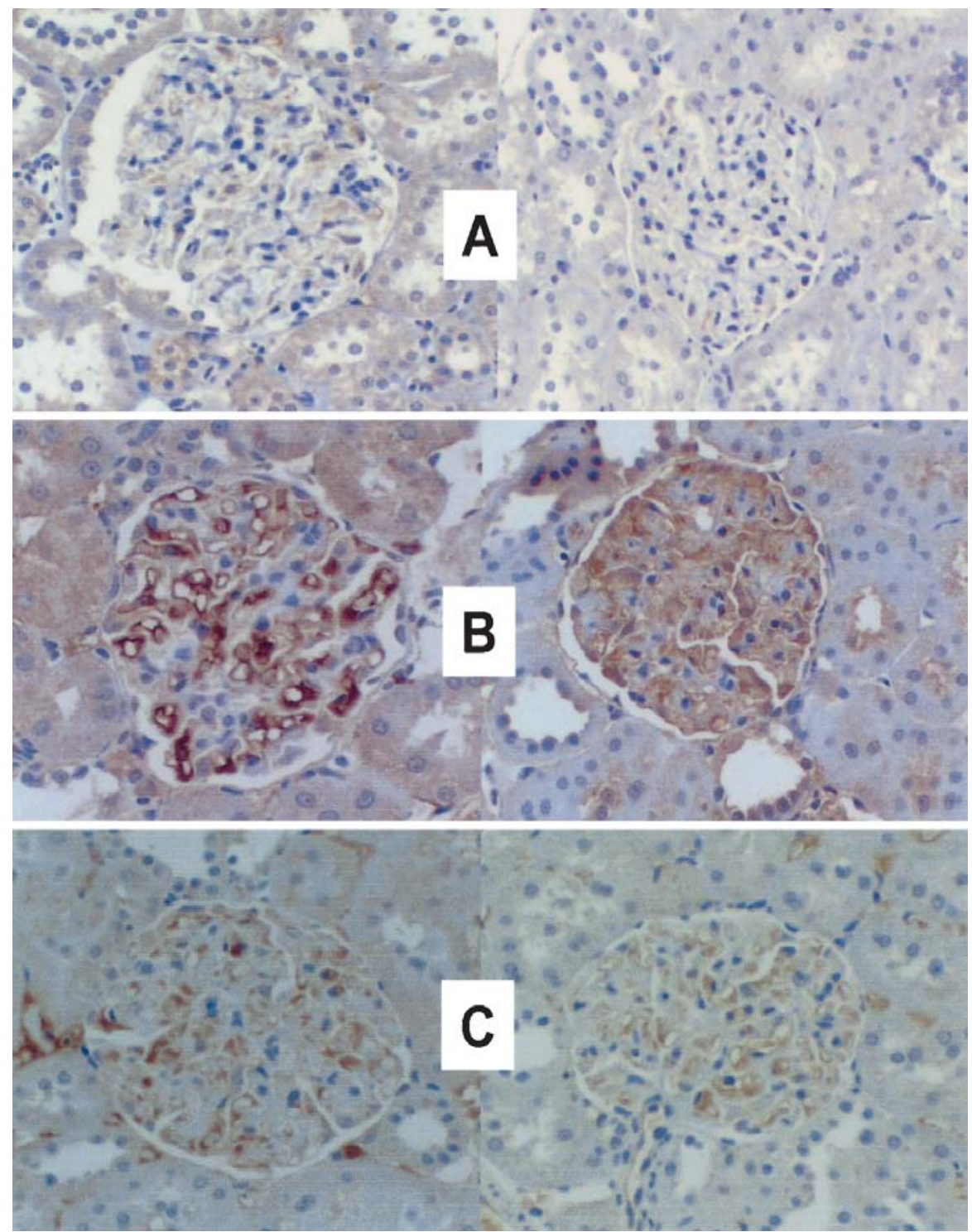

Fig. 7. Comparison of immunohistochemical staining for AGE in renal glomeruli and mesangial matrix. Formalin-fixed kidney sections ( $2 \mu \mathrm{m}$ thick) taken from representative rats from each treatment group at 32 weeks were mounted on slides and baked for $3 \mathrm{~h}$ at $58^{\circ} \mathrm{C}$. The slides were deparaffinized and rinsed with $3 \%$ hydrogen peroxide for $5 \mathrm{~min}$. Proteinase $\mathrm{K}$ $(0.5 \mathrm{mg} / \mathrm{ml})$ was added for $5 \mathrm{~min}$ and the sections were blocked with serum-free Protein Blocking Agent. Primary antibody (anti-AGE monoclonal 6D12 diluted 1:100) was then added for $30 \mathrm{~min}$, followed by peroxidase-labelled polyclonal anti mouse IgG antibody for $30 \mathrm{~min}$. Localization of peroxidase conjugates was revealed using diaminobenzidine tetrahydrochloride (DAB) solution as chromogen and haematoxylin as counterstain. (A) non-diabetic; (B), diabetic; (C) diabetic + LR-90. Results shown are representative images from two different kidney samples from each group

molecules, and which was also shown to lower serum chlolesterol and low-density lipoproteins (LDL) in rats [53]. Our previous in vitro studies documented that LR-90 inhibits AGE formation, and also showed that this compound is a more potent inhibitor of AGEprotein cross-linking and post Amadori-derived AGE than aminoguanidine and pyridoxamine [27, 41].

Over the last decade, evidence has accumulated implicating AGE and AGE-protein cross-linking as a major factor in the pathogenesis of diabetic nephropathy. Administration of AGE to non-diabetic rats leads to glomerulosclerosis and albuminuria, indicating that AGE alone could be sufficient to cause renal injury in diabetes [19]. Our present studies showed that LR-90treated diabetic rats showed statistically significant improvement in renal function in terms of development of proteinuria and reduction in creatinine excretion. Histochemical observations indicate that LR-90 reduced the incidence of glomerulosclerosis, cortical tubule degeneration and collagen deposition in the kidney compared to untreated diabetic rats. LR-90 treatment also effectively inhibited the increase of serum AGE and the in situ accumulation of immunoreactive AGE in collagen tissues and kidneys of diabetic rats. These results are consistent with previous in vivo 

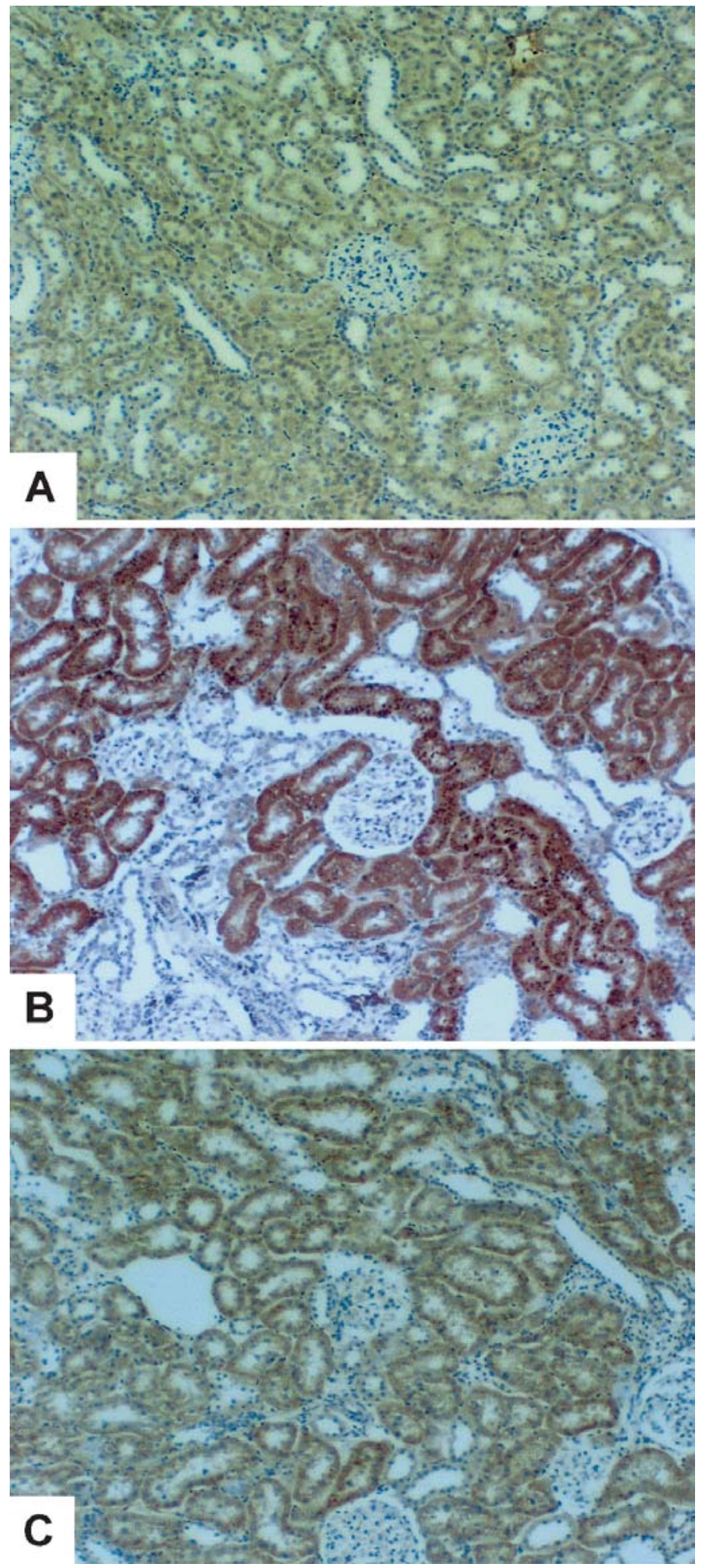

Fig. 8A-C. Immunohistochemical staining for renal nitrotyrosine. Formalin-fixed kidney sections ( $5 \mu \mathrm{m}$ thick) taken from representative rats from each treatment group at 32 weeks were mounted on slides and stained with anti-nitrotyrosine polyclonal antibodies. (A) non-diabetic; (B), diabetic; (C) diabetic + LR-90. Results shown are representative images from different kidney samples from each group

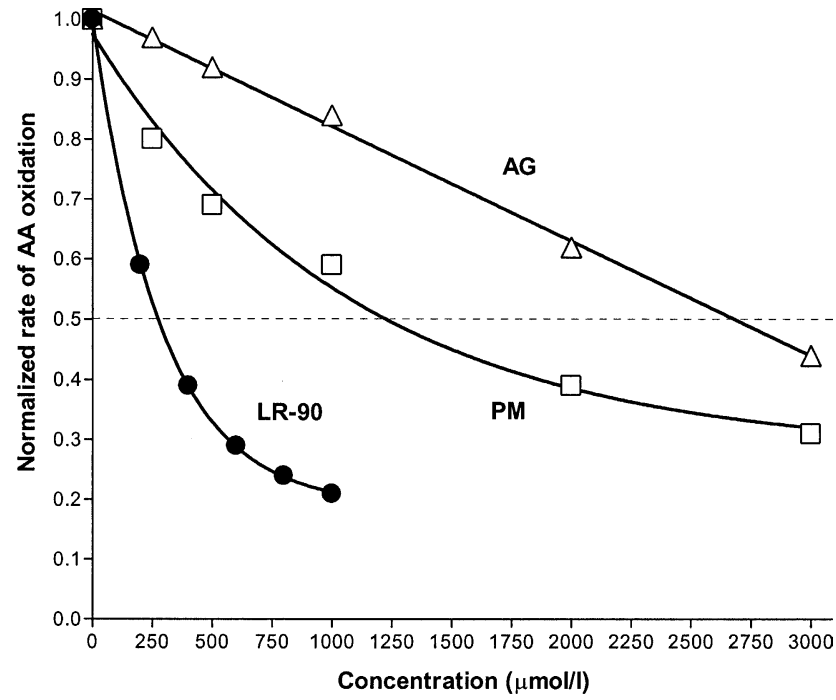

Fig. 9. Inhibition of $\mathrm{Cu} 2+$-catalysed oxidation of ascorbic acid by LR-90 compared to known AGE inhibitors. The kinetics of copper-catalysed oxidation of ascorbic acid (AA) were measured by RP-HPLC from reaction mixtures of $500 \mu \mathrm{mol} / \mathrm{l} \mathrm{AA}$, $500 \mathrm{nmol} / \mathrm{l} \mathrm{CuCl}{ }_{2}$, and various concentrations of LR-90, PM and $\mathrm{AG}$ in $20 \mathrm{mmol} / \mathrm{l}$ chelex-treated phosphate buffer. Dashed horizontal line indicates $50 \%$ loss of AA

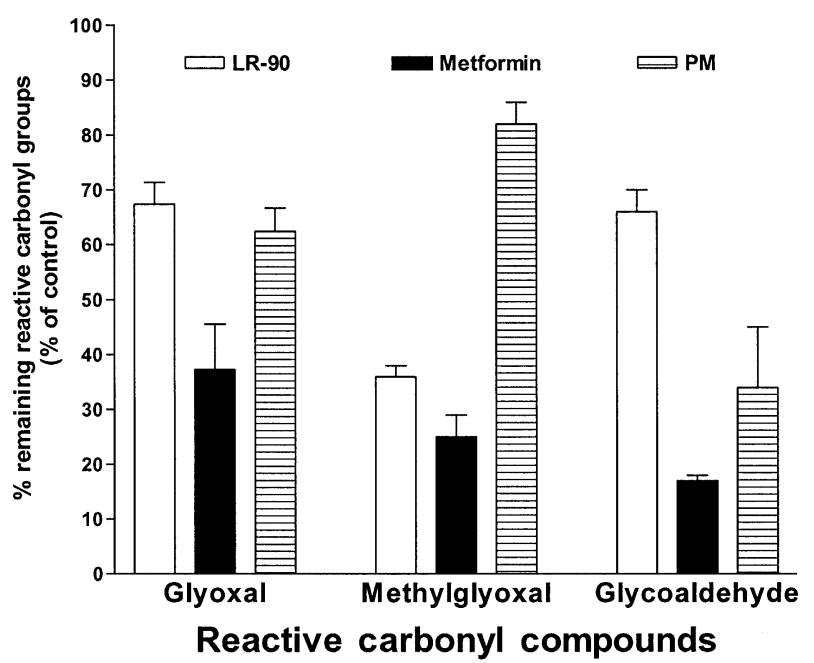

Fig. 10. Carbonyl trapping activities of LR-90 compared with known AGE inhibitors. Samples of GO (10 mmol/l), MGO (10 $\mathrm{mmol} / \mathrm{l})$ and GLA $(10 \mathrm{mmol} / \mathrm{l})$ were incubated with $15 \mathrm{mmol} / \mathrm{l}$ of each compound at $37^{\circ} \mathrm{C}$ in $200 \mathrm{mmol} / \mathrm{l}$ phosphate buffer, $\mathrm{pH} 7.5$ with $0.02 \%$ sodium azide for $24 \mathrm{~h}$ (GO and MGO) or $72 \mathrm{~h}$ (GLA). The loss of carbonyl moieties in the course of reaction was measured spectrophotometrically using either Girard's $\mathrm{T}$ reagent $(\mathrm{GO}, \mathrm{MGO})$ or DNPH (GLA). Parallel experiments with RCS incubated under the same conditions but without the inhibitor compounds were used as reference for calculating the relative amount of remaining reactive carbonyl groups

studies suggesting that AGE inhibitors confer renoprotective effects. However, we have used LR-90 at least 50 times less concentration on a molar basis than what has been traditionally used with AG, ALT-946 and PM, three model AGE inhibitors with good potential for treatment of diabetic nephropathy [36, 42, 43, 
49]. We also found that LR-90-treated rats weigh more than untreated diabetic animals, and few rats in this treatment group were observed to still contain some amount of fat deposits in their body wall (which was completely absent from untreated diabetic animals). This action of LR-90 is currently unexplained since the compound had no effect on blood glucose and concentrations of glycated haemoglobin. These findings suggest that this compound could have some other metabolic effects other than inhibiting AGE formation.

Although aldose and ketose sugars were originally thought to be the sole precursors of AGE, current research indicate that RCS generated from carbohydrate, lipid and amino acid metabolisms such as MGO, GO, GLA, dehydroascorbate, 3-deoxyglucosone and malondialdehyde, are even more reactive and are potent precursors of AGE formation and protein cross-linking $[6,7,8,9,10,54,55,56]$. Known AGE inhibitors with renoprotective effects such AG, PM, and OPB-9195 are thought to prevent AGE accumulation by interacting with these highly reactive RCS and acting as carbonyl traps, thereby limiting oxidative damage to tissues. AG reacts with $\alpha$-dicarbonyls GO, $\mathrm{MGO}$ and 3-deoxyglucosone to form triazine derivatives $[57,58]$, whereas PM was recently shown to interact and form adducts with GO, GLA, and MGO $[52,59]$. It has also been suggested that the chelating activity of AGE inhibitors and breakers at therapeutic concentrations could contribute to their inhibition of AGE formation and protection against development of diabetic complications [51].

The mechanism of action of LR-90 is still not clear, but our in vitro studies indicate that it is a potent chelator of $\mathrm{Cu}^{2+}$ (more potent than $\mathrm{AG}$ and PM) and it inhibits oxidation of ascorbic acid to dehydroascorbate. It also has the ability to interact with several RCS such as GO, MGO and GLA, compounds that readily modify lysine, arginine and cysteine residues on proteins. It is therefore likely that the carbonyl trapping properties of LR-90, and/or possibly its metal chelating activity which can interfere with glycoxidative AGE formation, is mediating the renoprotective effect of this compound. Although we have not yet identified the products or adducts between LR-90 and these RCS, we have observed in vitro that this compound rapidly reacts with GO, MGO and GLA, and also prevents formation of protein cross-links derived from MGO-lysozyme interaction.

Recent in vitro and in vivo studies indicate that CML and AGE-albumin can induce $\mathrm{NF}_{\kappa} \mathrm{B}$ activation in proximal endothelial cells, perpetuating an increase in pro-inflammatory gene products that can damage the renal tubules $[60,61]$. In addition, binding of AGE with their receptors such as RAGE is known to enhance the formation of RAS with subsequent activation of $\mathrm{NF}_{\mathrm{K}} \mathrm{B}$ and release of various cytokines, growth factors, and adhesion molecules [62, 63]. As seen in our study, both lymphocytes and neutrophil infiltrates were observed in the renal interstitium of diabetic rats, which were reduced by LR-90 treatment. Based on this data, we suspect that this new compound could block the inflammation pathways by interfering with AGE formation and protein cross-linking.

Our data with nitrotyrosine formation in renal cortex, a marker of protein oxidation and index of damage related to reactive nitrogen species, showed that LR-90-treatment could decrease oxidative damage to renal tissues. It has been suggested that increased nitrotyrosine concentrations play a major role in early diabetic tubular damage and in the progression of renal disease [64]. Proximal tubular cells produce nitric oxide (NO), which can react with superoxide to form peroxynitrite (ONOO-), a powerful oxidant. Peroxynitrite nitrosylates tyrosine moieties on proteins, producing nitrotyrosine $[65,66]$. In vitro studies have suggested that glycation itself can result in the production of superoxide and hydroxyl radicals through transition metal catalysis [9, 67, 68, 69]. Alternatively, ROS generation could involve AGE-RAGE interaction through stimulation of membrane-bound NADPH oxidase [70]. Whether LR-90's interaction with RCS and inhibitory action on AGE formation has some effect on ROS production has not been determined. Also, we cannot rule out the possibility that LR-90 has some effect on NO synthetase (and subsequent NO production) and NADPH oxidase since we did not carry out experiments to test these two possible pathways leading to increased nitrotyrosine production. More recently, a study [50] showed that the increase in CML-AGE and nitrotyrosine staining in rats with diabetic nephropathy can be attenuated by ramipril and aminoguanidine, indicating that $\mathrm{ACE}$ inhibition and blockage of AGE formation could involve common pathways such as ROS formation.

How can LR-90 affect AGE formation and free radical generation? At this point, we can only speculate that the strong metal chelation property of LR-90 has the potential to inhibit the autooxidation pathways before and after the formation of RCS, thereby preventing AGE formation and the subsequent free radical generation. Studies on numerous AGE inhibitors and their metal chelating properties showed that these compounds inhibit the autoxidation of ascorbate, prior to the formation of RCS [51]. A recent study suggests that ascorbate could be the primary source of increased chemical modification of proteins in STZ-diabetic rats, as its oxidation product, dehydroascorbate, is also a potent source of both CML and pentosidine [43]. Morever, recent experiments [71] indicate that metal-catalysed oxidation plays a critical role in glucose-induced modifications of the collagen. They observed that transition metals like copper ions can catalyse both glycation (covalent binding of glucose to collagen) and glycoxidation (oxidation of glycated collagen) in a concentration-dependent manner. Of 
major interest along this context is the suggestion that the glycoxidation-derived CML and possibly other glycated proteins can complex with redox active metals, creating a protein-metal redox active center that could generate free radicals and initiate hydroxy-radical mediated tissue damage [72, 73, 74]. By gradually removing free metal ions from tissues and plasma for excretion in urine, LR-90 could decrease the overall metal-catalysed oxidative damage to proteins in vivo. Additionally, by inhibiting glycoxidation, LR-90 could also delay AGE formation and protein crosslinking, which in turn can reduce free radical production. This was clearly evident from the results of our experiments: the less CML-AGE detected in kidneys, the less AGE-collagen cross-linking in tissues, which eventually resulted to less kidney damage as indicated by reduced incidence of glomerulosclerosis, collagen and nitrotyrosine deposition in the kidney, and lower albumin and creatinine excretions. Nonetheless, our in vitro observation that LR-90 is a potent ribose-derived post-Amadori AGE formation inhibitor [27] suggests that LR-90's effect might not be purely by metal chelation because it is known that browning and crosslinking of proteins by pentoses is independent of metal-catalysed oxidation chemistry [75]. Also, previous studies indicate that only $50 \%$ of CML formation originate from oxidation of the Amadori product, and the rest from a pre-Amadori stage largely independent of glucose autoxidation [76]. Thus, to what extent does the metal chelator property of LR-90 affect RCS and ROS production or propagation remains to be investigated. In vivo measurements of glycoxative AGE products such CML and pentosidine, RCS, as well as isolation of products formed between LR-90, RCS and post-Amadori intermediates would help clarify these issues. Measurements of chelatable metals in non-diabetic versus LR-90-treated animals should also provide some information about the mechanism of action of this new compound. More recent mechanistic studies on PM suggests that this compound exerts its action not by binding to post-Amadori and carbonyl intermediates which was previously thought, but probably by interfering with redox metal ions required for glycoxidative AGE formation [77].

In summary, this study provides preliminary evidence suggesting that LR-90 could be an effective treatment for early renal disease and possibly other diabetic complications where accumulation of AGEs and intermediate compounds are primary contributors. In this regard, we speculate that LR-90 inhibits accumulation of circulating AGE and AGE deposition in tissues either by interfering with metal-catalysed redox reactions of glycoxidative AGE pathways and/or by direct interaction with RCS to prevent AGE formation and protein cross-linking.
Acknowledgements. This work was supported in part by research grants from R.W Johnson Pharmaceutical Research Institute and the Ella Fitzgerald Charitable Foundation. The authors would like to thank E. Sepulveda and N. Gonzales for the preparation of the manuscript and figures, and the City of Hope Electron Microscope Core Laboratory for the electron microscopy studies.

\section{References}

1. Bucala R, Cerami A (1992) Advanced glycosylation: chemistry, biology, and implications for diabetes and aging. Adv Pharmacol 23: 1-34

2. Brownlee M (1995) Advanced protein glycosylation in diabetes and aging. Ann Rev Med 46:223-234

3. Singh R, Barden A, Mori T, Beilin L (2001) Advanced glycation end-products: a review. Diabetologia 44: 129146

4. Schleicher ED, Bierhaus A, Haring HU, Nawroth, Lehmann R (2001) Chemistry and pathobiology of advanced glycation end products. Contrib Nephrol 131:1-9

5. Vlassara H, Palace MR (2002) Diabetes and advanced glycation endproducts. J Intern Med 251:87-101

6. Miyata T, Kurokawa K, De Strihou CVY (2000) Advanced glycation and lipoxidation end products: role of reactive carbonyl compounds generated during carbohydrate and lipid metabolism

7. Baynes JW, Thorpe SR (1999) Role of oxidative stress in diabetic complications: a new perspective on an old paradigm. Diabetes 48:1-9

8. Wolff SP, Bascal ZA, Hunt JV (1989) Autoxidative glycosylation: free radicals and glycation theory. Prog Clin Biol Res 304:259-275

9. Wolff SP, Jiang, ZY, Hunt JV (1991) Protein glycation and oxidative stress in diabetes mellitus and ageing. Free Radic Biol and Med 10:339-352

10. Loske C, Gerdemann A, Schepl et al. (2000) Transition metal-mediated glycoxidation accelerates cross-linking of beta-amyloid peptide. Eur J Biochem 267:4171-4178

11. Scivittaro V, Ganz MB, Weiss MF (2000) AGEs induce oxidative stress and activate protein kinase C-beta (II) in neonatal mesangial cells. Am J Physiol Renal Physiol 278: F676-F683

12. Suzuki D, Miyata T, Saotome N et al. (1999) Immunohistochemical evidence for an increased oxidative stress and carbonyl modification of proteins in diabetic glomerular lesions. J Am Soc Nephrol 10:822-832

13. Miyata T, Wada Y, Cai Z et al. (1997). Implications of an increased oxidative stress in the formation of advanced glycation endproducts in patients with end stage renal failure. Kidney Int 51:1170-1181

14. Friedman EA (1999) Advanced glycation end-prodcuts in diabetic nephropathy. Nephron Dial Transplant 14 [Suppl. 3]:1-9

15. Mogensen CE (1999) Microalbuminuria, blood pressure and diabetic renal disease: origin and development of ideas. Diabetologia 42:263-285

16. Lehmann R, Schleicher ED (2000) Molecular mechanism of diabetic nephropathy. Clin Chim Acta 297:135-144

17. Yamamoto Y, Kato I, Doi T et al. (2001) Development and prevention of advanced diabetic nephropathy in RAGEoverexpressing mice. J Clin Invest 108:261-268

18. Makita Z, Radoff S, Rayfield EJ et al. (1991) Advanced glycation endproducts in patients with diabetic nephropathy. N Engl J Med 325:836-842 
19. Vlassara H, Fuh H, Makita Z, Li YM, Steffes M (1994) Advanced glycation end-products induce glomerular sclerosis and albuminuria in normal rats. Proc Natl Acad Sci USA 91:11704-11708

20. Bendayan M (1998) Immunocytochemical detection of advanced glycated end products in rat renal tissue as a function of age and diabetes. Kidney Int 54:438-447

21. Imai N, Nishi S, Suzuki Y et al. (1997) Histological localization of advanced glycosylation end products in the progression of diabetic nephropathy. Nephron 76:153-160

22. Horie K, Miyata T, Maeda K et al. (1997) Immunohistochemical colocalization of glycoxidation products and lipid peroxidation products in diabetic renal glomerular lesions. J Clin Invest 100:2995-3004

23. Heidland A, Sebekova K, Schinzel R (2001) Advanced glycation end products and the progressive course of renal disease. Am J Kidney Dis 38 [4 Suppl 1]:S100-S1006

24. Aronson D (2002) Potential role of advanced glycosylation end products in promoting restenosis in diabetes and renal failure. Med Hypotheses 59:297-301

25. Bailey AJ, Paul RG, Knott L (1998) Mechanisms of maturation and ageing of collagen. Mech Ageing Dev 106:1-56

26. Dukic-Stefanovic S, Schinzel R, Riederer P, Munich G (2001) AGEs in the brain: AGE-inhibitors as neuroprotective and anti-dementia drugs. Biogerontology 2:19-34

27. Rahbar S, Figarola JL (2002) Inhibitors and breakers of advanced glycation endproducts. Curr Med Chem-Immunol Endocrin Metabol 2:174-186

28. Brownlee M, Vlassara H, Kooney A, Ulrich P, Cerami A (1986) Aminoguanidine prevents diabetes-induced arterial wall protein cross-linking. Science 232:1629-1632

29. Hammes HP, Martin S, Federin K, Geisen K, Brownlee M (1991) Aminoguanidine treatment inhibits the development of experimental diabetic retinopathy. Proc Natl Acad Sci USA 88:11555-11558

30. Bonnefont-Rousselot D (2001) Antioxidant and anti-AGE therapeutics: evaluation and perspectives. J Soc Biol 195: 391-398

31. Booth AA, Khalifah RG, Hudson BG (1996) Thiamine pyrophosphate and pyridoxamine inhibit the formation of antigenic advanced glycation end-products: comparison with aminoguanidine. Biochem Biophys Res Commun. 220:113-119

32. Suzuki YJ, Tsuchiya M, Packer L (1992) Lipoate prevents glucose-induced protein modifications. Free Radic Res Commun 173:211-217

33. Onorato JM, Jenkins AJ, Thorpe SR, Baynes JW (2000) Pyridoxamine, an inhibitor of advanced glycation reactions, also inhibits advanced lipoxidation reactions: mechanism of action of pyridoxamine. J Biol Chem 275:2117721184

34. Ruggiero-Lopez D, Lecomte M, Moinet G, Patereau G, Lagarde M, Wiernsperger N (1999) Reaction of metformin with dicarbonyl compounds. Possible implication in the inhibition of advanced glycation end product formation. Biochem Pharmacol 58:1765-1773

35. Nakamura S, Makita Z, Ishikawa S et al. (1997) Progression of nephropathy in spontaneous diabetic rats is prevented by OPB-9195, a novel inhibitor of advanced glycation. Diabetes 46:895-899

36. Forbes JM, Soulis T, Thallas V et al. (2001) Renoprotective effects of a novel inhibitor of advanced glycation. Diabetologia 44:108-114

37. Ninomiya T, Tsutsumi S, Kawaguchi M (2001) EF655, a novel AGE production inhibitor, prevents progression of diabetic nephrophaty in STZ-induced diabetic rats. American Diabetes Association 61st Scientific Session, Philadelphia, PA (Abstract No 724-P)
38. Vasan S, Zhang X, Zhang, XI et al.(1996) An agent cleaving glucose-derived protein cross-links in vitro and in vivo. Nature 382:275-278

39. Vaitkevicius PV, Lane M, Spurgeon H et al. (2000) A cross-link breaker has sustained effects on arterial and ventricular properties of older rhesus monkey. Proc Natl Acad Sci USA 98:1171-1175

40. Rahbar S, Yernini K, Scott S, Gonzales N, Lalezari I (1999) Novel inhibitors of glycation endproducts. Biochem Biophys Res Commun 262:651-656

41. Rahbar S, Yerneni K, Scott S, Gonzales N, Lalezari I (2000) Novel inhibitors of advanced glycation endproducts (Part II). Mol Cell Biol Res Comm 3:360-366

42. Soulis-Liparota T, Cooper M, Papazoglou D, Clarke B, Jerums G (1991). Retardation of aminoguanidine of development of albuminuria, mesangial expansion and tissue fluorescence in streptozotocin-induced diabetic rats. Diabetes 40:1328-1334

43. Degenhardt TP, Alderson NL, Arrington DD et al. (2002) Pyridoxamine inhibits early renal disease and dyslipidemia in streptozotocin-diabetic rats. Kidney Int 61:939-950

44. Al-Abed Y, Kapurniotu A, Bucala R (1999) Advanced glycation end products: detection and reversal. Methods Enzymol 309:152-172

45. Kochakian M, Manjula BN, Egan JJ (1996) Chronic dosing with aminoguanidine and novel advanced glycosylation end product-formation inhibitors ameliorates cross-linking of tail tendon collagen in STZ-induced diabetic rats. Diabetes 45:1694-1700

46. Stefek M, Gajdosik A, Gajdosikova A, Krizanova L (2000) $p$-Dimethyl aminobenzaldehyde-reactive substances in tail tendon collagen of streptozotocin-diabetic rats: temporal relation to biomechanical properties and advanced glycation endproduct (AGE)-related fluorescence. Biochim Biophys Acta 1502:398-404

47. Creemers LB, Jansen DC, van Veen-Reurings A, van den Bos T, Everts V (1997) Microassay for the assessment of low levels of hydroxyproline. Biotechniques 22:656-658

48. Verzij1 N, DeGroot J, Oldehinkel E et al. (2000) Age-related accumulation of Maillard reaction products in human articular cartilage collagen. Biochem J 350:381-38

49. Wilkinson-Berka JL, Kelly DJ, Koerner SM et al. (2002) ALT-946 and aminoguanidine, inhibitors of advanced glycation, improve severe nephropathy in the diabetic transgenic (mREN-2) 27 rat. Diabetes 51:3283-3289

50. Forbes JM, Cooper ME, Thallas V et al. (2002) Reduction of the accumulation of advanced glycation end products by ACE inhibition in experimental diabetic nephropathy. Diabetes 51:3274-3282

51. Price DL, Rhett PM, Thorpe SR, Baynes JW (2001) Chelating activity of advanced glycation end-products inhibitors. J Biol Chem 276:48967-48972

52. Voziyan PA, Metz TO, Baynes JW, Hudson BG (2002) A post-Amadori inhibitor pyridoxamine also inhibits chemical modification of proteins by scavenging carbonyl intermediates of carbohydrate and lipid degradation. J Biol Chem 277:3397-3403

53. Lalezari I, Rahbar S, Lalezari P, Fermi G, Perutz MF (1988) LR16, a compound with potent effects on the oxygen affinity of hemoglobin, on blood cholesterol, and on low density lipoprotein. Proc Natl Acad Sci USA 85:6117-6121

54. Lyons T, Jenkins AJ (1997) Glycation, oxidation and lipoxidation in the development of the complications of diabetes mellitus: a 'carbonyl stress' hypothesis. Diabetes Rev 5:365-391

55. Thornalley PJ, Langborg A, Minhas HS (1999) Formation of glyoxal, methylglyoxal and 3-deoxyglucosone in the glycation of proteins by glucose. Biochem J 344:109-116 
56. Miyata T, Saito A, Kurokawa K, van Ypersele de Strihou C (2001) Advanced glycation and lipoxidation end products: reactive carbonyl compounds-related uraemic toxicity. Nephrol Dial Transplant 16 [Suppl 4]:8-11

57. Lo TW, Selwood T, Thornalley PJ (1994) The reaction of methylglyoxal with aminoguanidine under physiological conditions and prevention of methylglyoxal binding to plasma proteins. Biochem Pharmacol 48:1865-70

58. Thornalley PJ, Yurek-George A, Argirov OK (2000) Kinetics and mechanism of the reaction of aminoguanidine with the alpha-oxoaldehydes glyoxal, methylglyoxal, and 3-deoxyglucosone under physiological conditions. Biochem Pharmacol 60:55-65

59. Nagaraj RH, Sarkay P, Mally A, Biemel KM, Lederer MO, Padayatti PS (2002) Effects of pyridoxamine on chemical modifications of proteins by carbonyls in diabetic rats: characterization of a major product from the reaction of pyridoxamine with metholglyoxal. Arch Biochem Biophys 402:110-119

60. Kislinger T, Fu C, Huber B et al. (1999) N(epsilon)-(carboxymethyl)lysine adducts of proteins are ligands for receptor for advanced glycation end products that activate cell signaling pathways and modulate gene expression. J Biol Chem 274:31740-31749

61. Morcos M, Sayed AA, Bierhaus A et al. (2002) Activation of tubular epithelial cells in diabetic nephropathy. Diabetes 51:3532-3544

62. Boulanger E, Wautier MP, Wautier JL et al. (2002) AGEs bind to mesothelial cells via RAGE and stimulate VCAM-1 expression. Kidney Int 61:148-156

63. Basta G, Lazzerini G, Massaro M et al. (2002) Advanced glycation end products activate endothelium through signal-transduction receptor RAGE: a mechanism for amplification of inflammatory responses. Circulation 105:816-822

64. Thuraisingham RC, Nott CA, Dodd SM, Yaqoob MM (2000) Increased nitrotyrosine staining in kidneys from patients with diabetic nephropathy. Kidney Int 57:968-972

65. Beckman JS, Koppenol WH (1996) Nitric oxide, superoxide, and peroxynitrite: the good, the bad, and ugly. Am J Physiol 271:C1424-C1437

66. Reiter CD, Teng RJ, Beckman JS (2000) Superoxide reacts with nitric oxide to nitrate tyrosine at physiological $\mathrm{pH}$ via peroxynitrite. J Biol Chem 275:32460-32466
67. Sakurai T, Tsuchiya S (1988) Superoxide production from nonenzymatically glycated protein. FEBS Lett 236:406410

68. Yim HS, Kang SO, Hah YC, Chock PB, Yim MB (1995) Free radicals generated during the glycation reaction of amino acids by methylglyoxal. A model study of proteincross-linked free radicals. J Biol Chem 270:28228-28233

69. Ortwerth BJ, James H, Simpson G, Linetsky M (1998) The generation of superoxide anions in glycation reactions with sugars, osones, and 3-deoxyosones. Biochem Biophys Res Commun 245:161-165

70. Wautier MP, Chappey O, Corda S, Stern DM, Schmidt AM, Wautier JL (2001) Activation of NADPH oxidase by AGE links oxidant stress to altered gene expression via RAGE. Am J Physiol Endocrinol Metab 280:E685-E694

71. Sajithal GB, Pandarinathan C, Chadrakasan G (1999) An in vitro study on the role of metal catalyzed oxidation in glycation and cross-linking of collagen. Mol Cell Biol 194: 257-263

72. Qian M, Liu M, Eaton JW (1998) Transition metals bind to glycated proteins forming redox active "glycochelates": implications for the pathogenesis of certain diabetic complications. Biochem Biophys Res Commun 250:385-389

73. Saxena AK, Saxena P, Wu X, Obrenovich M, Weiss MF, Monnier VM (1999) Protein aging by carboxymethylation of lysines generates sites for divalent metal and redox active copper binding: relevance to diseases of glycoxidative stress. Biochem Biophys Res Commun 260:332-338

74. Yim MB, Yim HS, Lee C, Kang SO, Chock PB (2001) Protein glycation: creation of catalytic sites for free radical generation. Ann NY Acad Sci 928:48-53

75. Litchfield JE, Thorpe SR, Baynes JW (1999) Oxygen is not required for the browning and cross-linking of protein by pentoses: relevance to Maillard reactions in vivo. Int J Biochem Cell Biol 1999 31:1297-1305

76. Glomb MA, Monnier VM (1995) Mechanism of protein modification by glyoxal and glycoaldehyde, reactive intermediates of the Maillard reaction. J Biol Chem 270: 10017-10026

77. Khalifah RG, Chen Y, Price DL, Booth AA (2002) Mechanism of inhibition of advanced glycation endproducts by Pyridorin $^{\mathrm{TM}}$, a novel therapeutic for diabetic complications. Diabetologia 45 [Suppl 2]:A1222 (Abstract) 